\title{
Young Anglers in Captivity and some of their Enemies. A study in a Plunger Jar.
}

\author{
By \\ Marie V. Lebour, D.Sc., \\ Naturalist at the Plymouth Laboratory.
}

With Figures 1-9 in the Text.

IT is only very rarely that the spawn of the Angler Lophius piscatorius is captured near Plymouth, although it has been recorded (Cunningham, 1896). It is well known that it consists of a gelatinous ribbon several yards long and a yard or more wide, with the eggs (over a million) in one layer divided from one another by roundish capsules. It is probable that the Angler spawns well out to sea, for when these ribbons of eggs have been captured anywhere near the coast the larvæ have nearly always already hatched and are lying loose in the capsules (Bowman, 1919). Moreover, most of the spawn caught inshore consists of portions only of the ribbon which have probably drifted towards the coast.

On June 18th, 1924, a piece of Angler spawn, measuring about five inches square, was caught by the Salpa in the Young Fish Trawl towing below the surface a few fathoms down, from Station L4, half-way between Rame Head and the Eddystone, Lat. $50^{\circ} 15^{\prime}$ N., $4^{\circ} 13^{\prime}$ W. The larvæ were all hatched and were moving about in the capsules, each capsule measuring about three to four millimetres across (Fig. 1, p. 722). Portions about an inch and a half square of this spawn were put into Plunger Jars (Brown, 1898; Lebour, 1922 and 1923), and kept alive. The fishes immediately began to hatch out from the capsules into the water, floating near the surface with the yolk sacs uppermost.

A good deal has already been written about larval and post-larval Anglers (Williamson, 1911 ; Bowman, 1919 ; Tåning, 1923 ; and others). It is, however, perhaps excusable to give a brief account of the present series which were reared for eleven days, and one drawn each day (Figs. $2,3,4)$. Unfortunately by the twelfth day all were dead, and it is interesting to note that they had reached the stage described by Williamson (1911) when his specimens ceased growing, although he kept some alive 
for several months. This stage is perhaps a critical one, and some special unknown factor is needed for the fishes to move forward.

The number of larval fishes hatched in one jar was far too many for the space, but it was found that some of the animals already established were eating them and keeping them down, therefore they were left, and some extremely interesting observations proved that some of the most delicate plankton organisms caught and ate young Anglers.

The temperature of the jars was not taken, but later observations

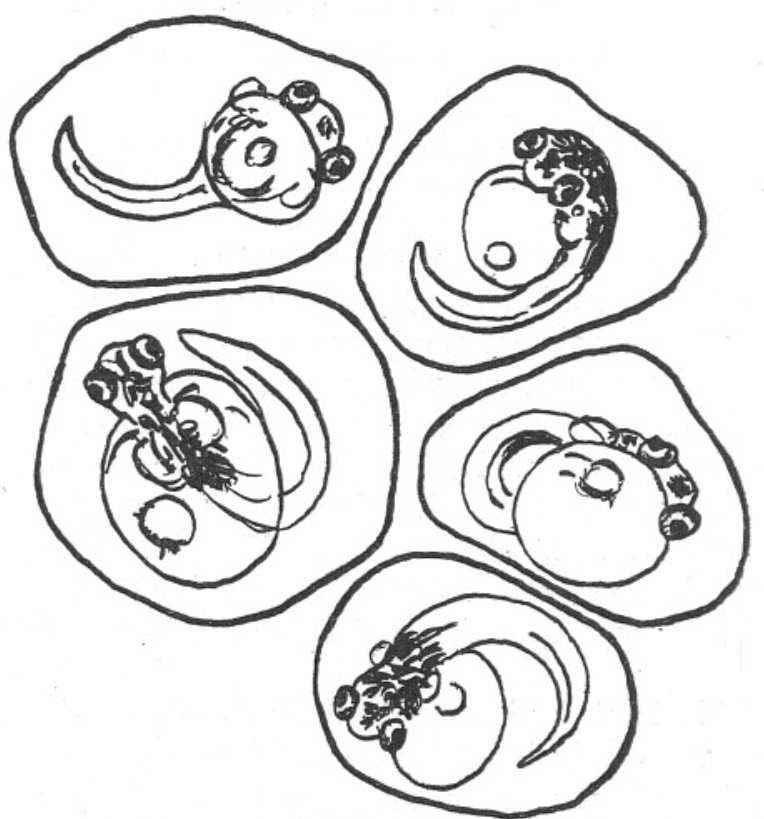

Fig. 1. Egg capsules of Angler, L4, June 18th, 1924, ca. 3-4 mm. across the capsule.

showed that they followed closely that of the main laboratory in which they were placed. In the following notes this latter temperature is given.

\section{DESCRIPTION OF THE YOUNG ANGLERS.}

June 18th, 1924. Age, 1st day. Length, $4.48 \mathrm{~mm}$. Temperature, 9.30 a.m., $16 \cdot 8^{\circ}$ C. ; 5 p.m., $20 \cdot 5^{\circ}$ C.

Fig. 2a. Large yolk sac. Mouth not formed. Head and body covered with large ramifying chromatophores forming a network over the front part. Simple broad larval fin round tail. Whole tail end 


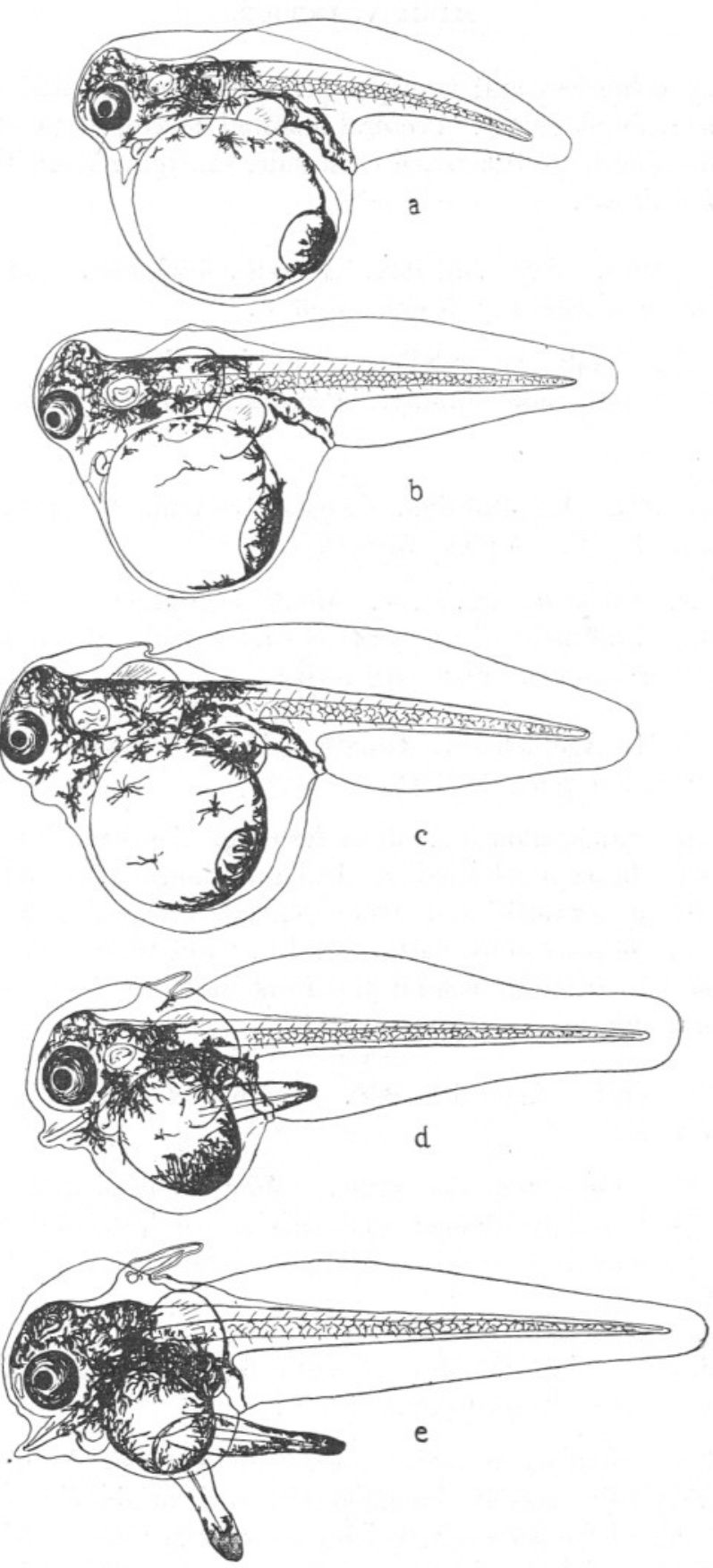

FIG. 2. Anglers, newly hatched to 5th day, from Plunger Jar. June 18th to 22nd, 1924.
(a) Newly hatched, $4 \cdot 48 \mathrm{~mm}$. long.
(c) 3rd day, $5.6 \mathrm{~mm}$. long.

(b) 2nd day, 4.96 mm. long.

(d) 4 th day, 5.6 $\mathrm{mm}$. long.

(e) 5th day, $6 \mathrm{~mm}$. long.

NEW SERIES. - vol. XIII. No. 3. MARCH, 1925. 
perfectly colourless and transparent. Rudiment of first dorsal fin shows as a simple hump. Pectoral fins well developed, pelvics behind them forming a protuberance each side, emerging from the dorsal part of yolk sac.

June 19th, 1924. Age, 2nd day. Length, 4.96 mm. Temperature, 9.30 a.m., $16 \cdot 8^{\circ}$ C. ; 5 p.m., $18 \cdot 3^{\circ} \mathrm{C}$.

Fig. 2b. Yolk sac smaller. Colouring the same. Rudiment of first dorsal more lumpy. Pectorals larger, pelvies slightly longer.

June 20th, 1924. Age, 3rd day. Length, 5.6 mm. Temperature, 9.30 a.m., $17 \cdot 2^{\circ}$ C. ; 5 p.m., $18 \cdot 8^{\circ} \mathrm{C}$.

Fig. 2c. Colouring the same. Mouth beginning to form, but not yet open. Rudiment of ray (3rd) of first dorsal. Pelvic fins longer and shifting forward. Fish very active.

June 21st, 1924. Age, 4th day. Length, $5 \cdot 6 \mathrm{~mm}$. Temperature, 9.30 a.m. $17 \cdot 9^{\circ}$ C. ; 1 p.m., $18 \cdot 2^{\circ} \mathrm{C}$.

Fig. 2d. Same colouring. Jaws forming. Anus much further forward and yolk sac much smaller. Tail much longer than body. Pelvic fins shifting forwards and more ventral, protruding horizontally behind and beyond anus, with central ray and black tip. A second ray (the 4th) forming behind the front ray (the true $3 \mathrm{rd}$ ) of the first dorsal fin.

June 22nd, 1924. Age, 5th day. Length, $6 \mathrm{~mm}$. Temperature not taken.

Fig. 2e. Colouring the same. Mouth conspicuous, but not open. Pelvic fins still longer, their origin now just below the origin of the pectorals. A true ray supports the first ray of the first dorsal fin.

June 23rd, 1924. Age, 6th day. Length, 6.5 mm. Temperature, 9.30 a.m., $17 \cdot 8^{\circ}$ C. ; 5.10 p.m., $18 \cdot 3^{\circ} \mathrm{C}$.

Fig. 3a. Colouring the same. Mouth almost open. Yolk sac nearly - gone. Pelvic fins greatly elongated with their origin slightly in front of the origin of the pectorals, which are now very large. The front ray of the first dorsal much longer, and the second, although still very short, supported by a true ray. Body very short. Tail more than three times as long as the head and trunk combined. 


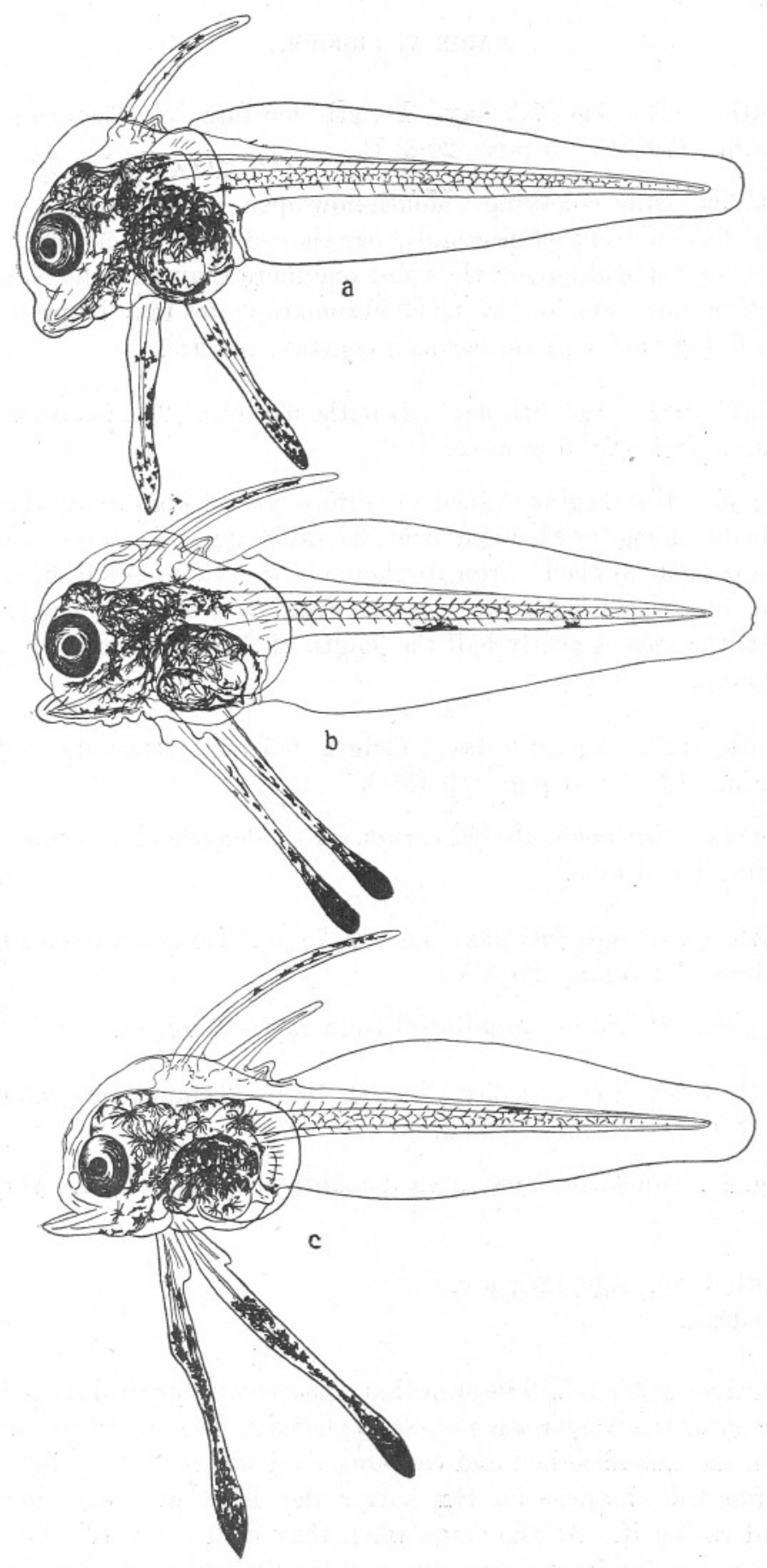

Fig. 3. Anglers, 6th to 8th day, June 23rd to 25th, 1924.

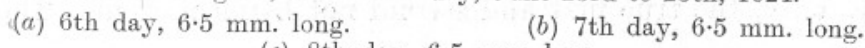
(c) 8 th day, $6.5 \mathrm{~mm}$. long. 
June 24th, 1924. Age, 7th day. Length, 6.5 mm. Temperature, 9.30 a.m., $17 \cdot 8^{\circ}$ C. ; 5 p.m., $20 \cdot 8^{\circ}$ C.

Fig. 3b. Same colouring. Mouth now open. Yolk sac almost gone. Pelvic fins in front of pectorals, oar-shaped with black tips. Two rays of first dorsal longer, the front one more than half the length of the pelvic fins. One or two black chromatophores may be present on the tail, but this is by no means a constant feature.

June 25th, 1924. Age, 8th day. Length, 6.5 mm. Temperature, 9.30 a.m. $18 \cdot 7^{\circ}$ C. ; 5 p.m., $22 \cdot 1^{\circ}$ C.

Fig. 3c. Fish begins to feed. A diffuse yellow appears on the head and body among the black pigment, the tail being still colourless except for an occasional black chromatophore or two, which are often absent. Pelvic fins longer with three rays. Front ray of first dorsal much longer, the second nearly half the length of the first, and a third just beginning.

June 26th, 1924. Age, 9th day. Length, 6.5 mm. Temperature, 9.30 a.m., $18^{\circ}$ C. ; 5 p.m., $19 \cdot 67^{\circ}$ C.

Fig. 4a. Not much altered except for the lengthening of the pelvic fins and dorsal rays.

June 27th, 1924. Age, 10th day. Length, $7 \mathrm{~mm}$. Temperature, 9.20 a.m., $18 \cdot 3^{\circ}$ C. ; 5 p.m., $20 \cdot 3^{\circ}$ C.

Fig. 4b. Pelvic fins and dorsal front ray still longer.

June 28th, 1924. Age, 11th day. Length, $7 \mathrm{~mm}$. Temperature, 9.30 a.m., $17 \cdot 9^{\circ}$ C. ; 1 p.m., $18 \cdot 6^{\circ}$ C.

Fig. 4c. Much the same, front dorsal ray slightly longer. Very few left.

June 29th, 1924. Age, 12th day.

All dead.

From these notes it will be seen that apparently a critical stage in the life history of the Angler was not, as might have been expected, directly the yolk sac was absorbed and catching food was necessary, but a few days after this, because for three days the fishes were catching food fast and eating it. At the sfage when they died the pelvic fins were very long, also the front dorsal ray, and the first dorsal fin consisted of three rays only, the true first and second not being present. The food 


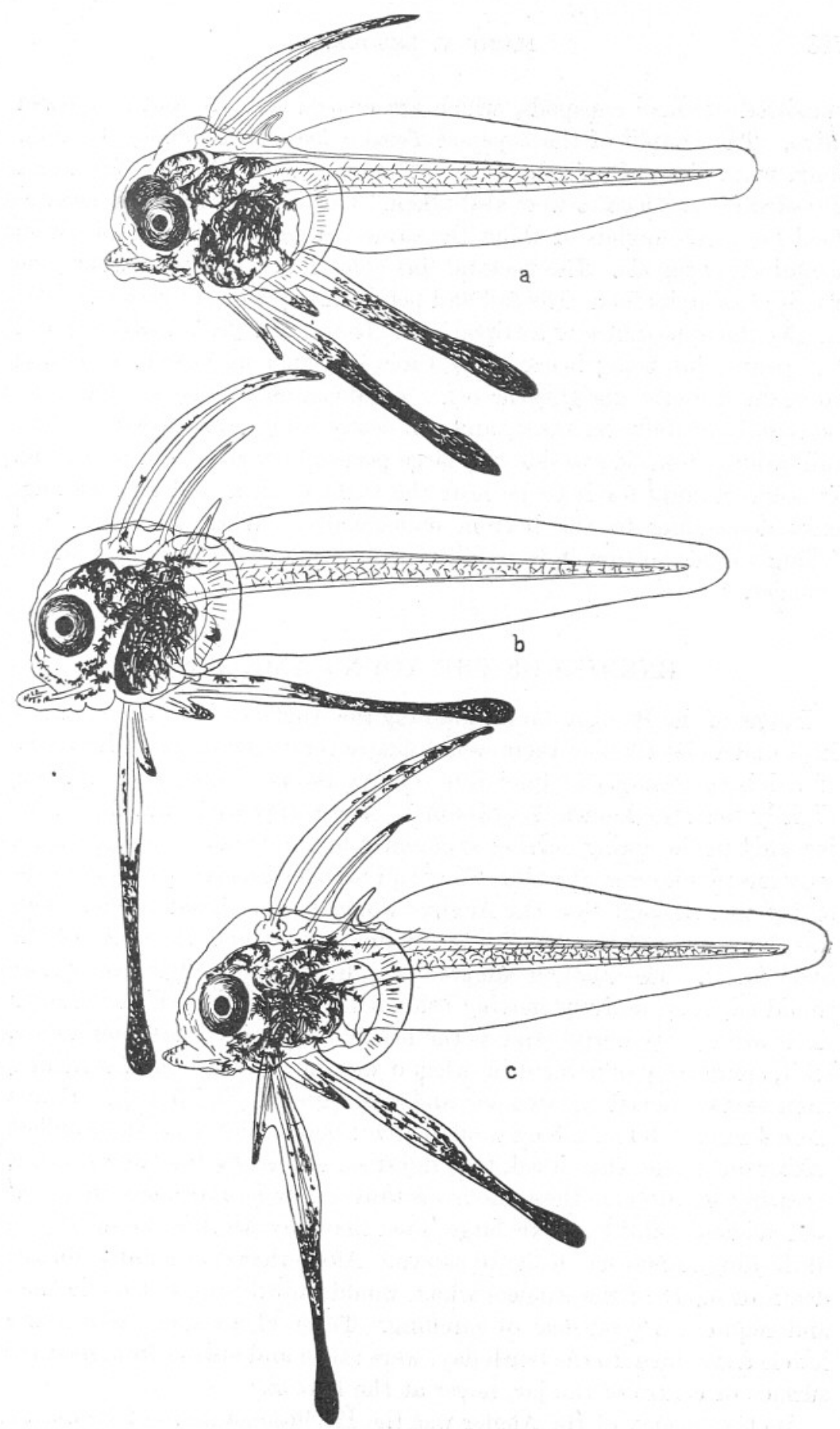

Fig. 4. Anglers, 9th to 11th day, June 26th to 28th, 1924.

(a) 9 th day, $6.5 \mathrm{~mm}$. long.
(c) lith day, $7 \mathrm{~mm}$. long. 
consisted of small copepods, which are chased cleverly and swallowed alive. The nauplii of the copepod Temora longicornis, about $0.4 \mathrm{~mm}$. long, was a favourite food. Older Temora and also Acartia Clausi and Pseudocalanus elongatus were also taken. This is apparently the natural food for small Anglers of about the same size taken from the plankton contained copepods. The pectoral fins come much into play whilst the fish is chasing its food. The tail and pelvic fins spread out give the little Angler the appearance of a tripod. The front crest (first dorsal fin) and the pelvic fins being black make three conspicuous processes coming from the fish, one upright, the other at almost equal angles. Thus the body is beautifully balanced, and can easily keep near the surface, the tail lashing from side to side, the large pectorals steering and balancing. It seems natural for it to be near the surface when well and feeding, only descending to the bottom occasionally. When moribund and falling to the bottom it is usually instantly devoured by some of its enemies.

\section{ENEMIES OF THE YOUNG ANGLERS.}

In one of the Plunger Jars containing the Anglers which was specially kept under observation, there were living several specimens of the young of a lobate ctenophore (probably Bolina infundibulum, but differing slightly from the known descriptions). These appeared suddenly in the jar early in the spring, having apparently been introduced as eggs when very fine plankton was put in. They had been feeding freely on copepods, and it was thought that the Anglers would be safe beside them. This was, however, not the case for the Bolina caught and ate many of the little fishes. The method adopted was interesting. The ctenophore would catch an actively moving fish with its tentacles, which although short are very powerful, and as the fish struggled the lobes would close on it, completely shutting it in, when it was quickly taken by the mouth, from there reached the stomach and was digested (Fig. 5 a-d). Bolina from $4 \mathrm{~mm}$. to $30 \mathrm{~mm}$. long would catch fishes in this way, the smallest taking one longer than itself, the largest sometimes taking two at a time or eating one after another. Bolina is thus seen to be extremely voracious and evidently able to tackle larger food than any previous knowledge of its feeding habits has hitherto shown. Altogether it accounted for the death of many of the Anglers which would quickly run out of the way and required a good deal of catching. Those of all ages, from newly hatched specimen to the tenth day, were taken and always from near the surface or centre of the jar, never at the bottom.

Another enemy of the Angler was the Phyllosoma larva of Palinurus, the Rock Lobster. These were fairly common in the outside plankton at 
this time. One caught with the Angler spawn was put into the same jar as the Bolinas. The Phyllosoma was seen to catch and eat the Anglers (Fig. 6 a-b, p. 730). Swimming about near the top of the jar it would encircle the fish with the endopodites of its long legs, the exopodites moving constantly and keeping up the body. In this way an effective
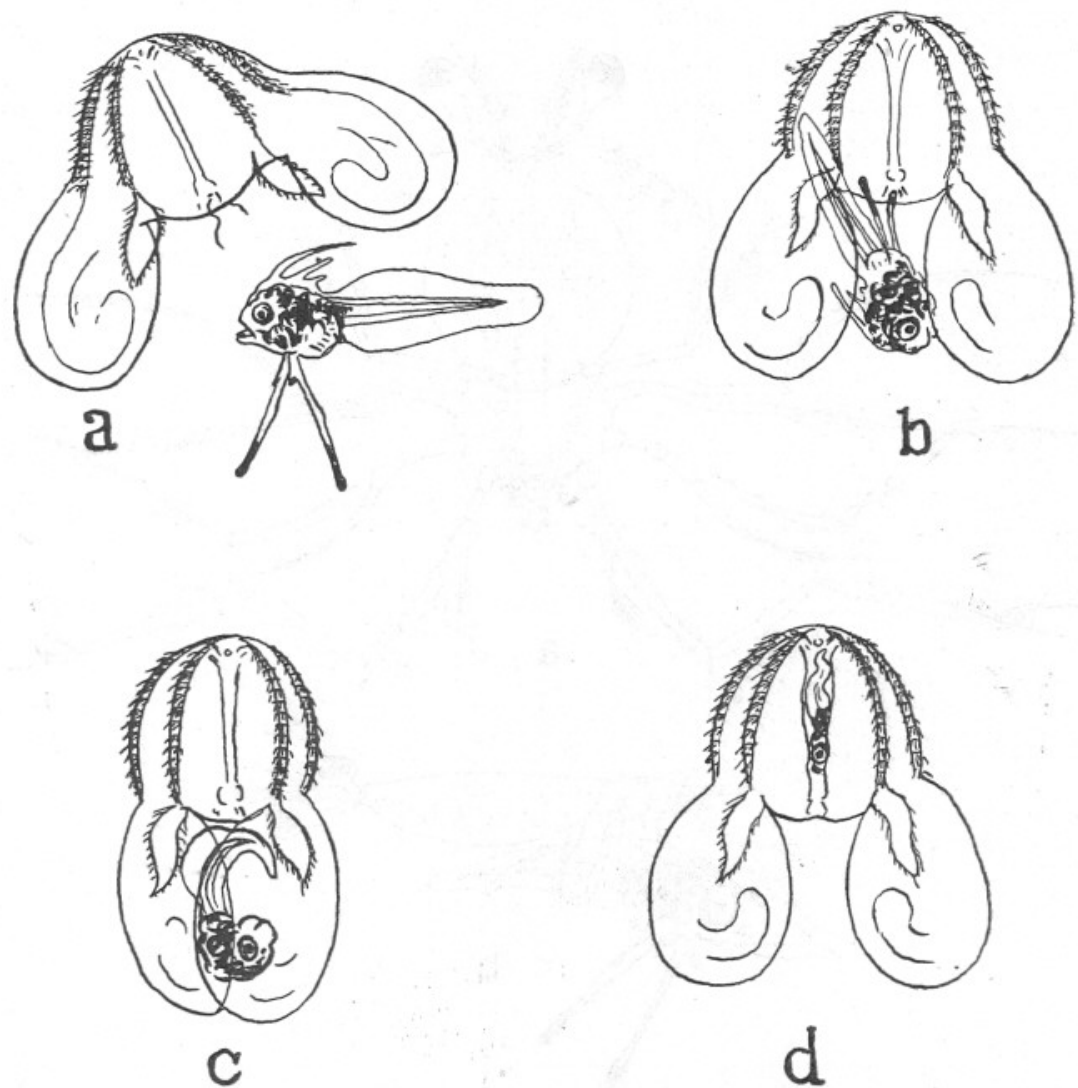

FIG. 5. Young Ctenophores (Bolina ?) catching baby Anglers in Plunger Jar.

(a) The Angler approaches.

(b) Is caught.

(c) Is taken into mouth.

(d) Is digested.

net was formed, the fish struggling but not able to escape, for probably it was pinched as well by the claws of the hind leg. Soon its struggles would cease, and it would be devoured. The Phyllosoma also ate copepods, which were visible inside it, but it was never actually seen to catch them. This beautiful glass-clear creature is a true enemy of little fishes. 
Many copepods were put in the Plunger Jar for food. Amongst these were a few specimens of Anomolocera Pattersoni. It has been noticed frequently by examining its stomach contents (Lebour, 1918; Marshall, 1924) that it is carnivorous, remains of copepods being very often found inside it, but in the jar they were actually seen to catch and eat the Anglers. These were caught when only a day or two old, three separate

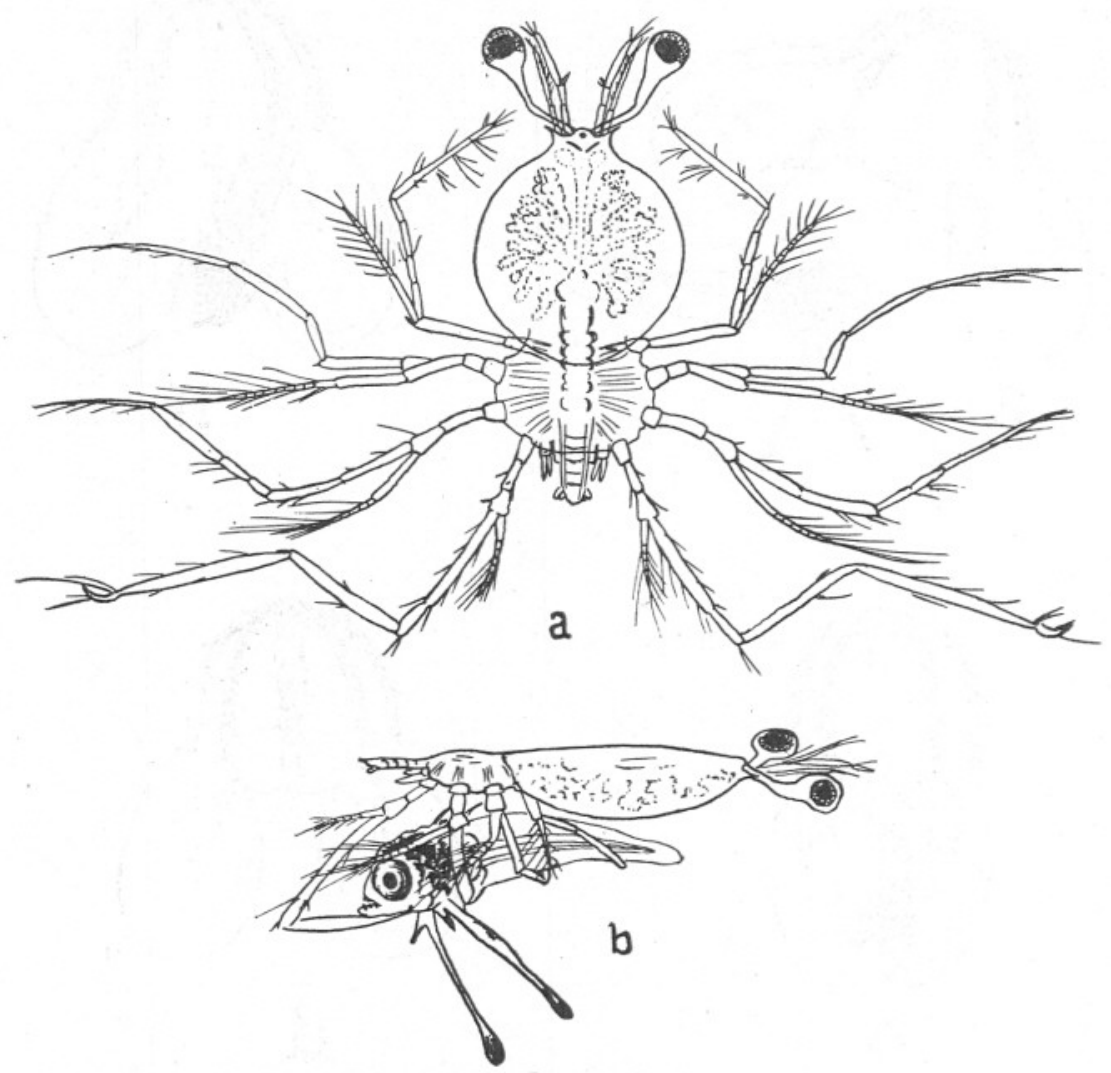

Fig. 6. Larva of Phyllosoma from Plunger Jar.

(a) Spread out, showing appendages.

(b) Catching a baby Angler.

Anomalocera, from 3 to $4 \mathrm{~mm}$. long, being seen to eat them. At this stage the fishes were not very active, but quite alive and well. They were caught near the surface by the appendages near the mouth, the mouth-parts and legs surrounding the head and body of the fish (Fig. 7).

There was another animal which fed on them when they went down to the bottom, in this case acting more as a scavenger than an enemy. 
This was a small hydroid (Clytia sp.) which was rapidly spreading on the floor of the jar. Each polyp (Fig. 8, p. 732) measured about $3 \mathrm{~mm}$. high, including its stalk, the individuals being joined by horizontal hyphæ. The tentacles were outspread and a small fish touching one of these would instantly set the rest in motion, a second polyp would then be agitated and possibly a third would join in, all three catching the fish and devouring it very quickly. In this way many little Anglers were caught within an hour, the hydroids being extraordinarily voracious.

This gives us some idea of the vicissitudes to which the little fishes are subjected in nature. They swim about catching their food where it is dense. With this food are also swimming about many other animals all on the look-out for food, many of them only too ready and eager to

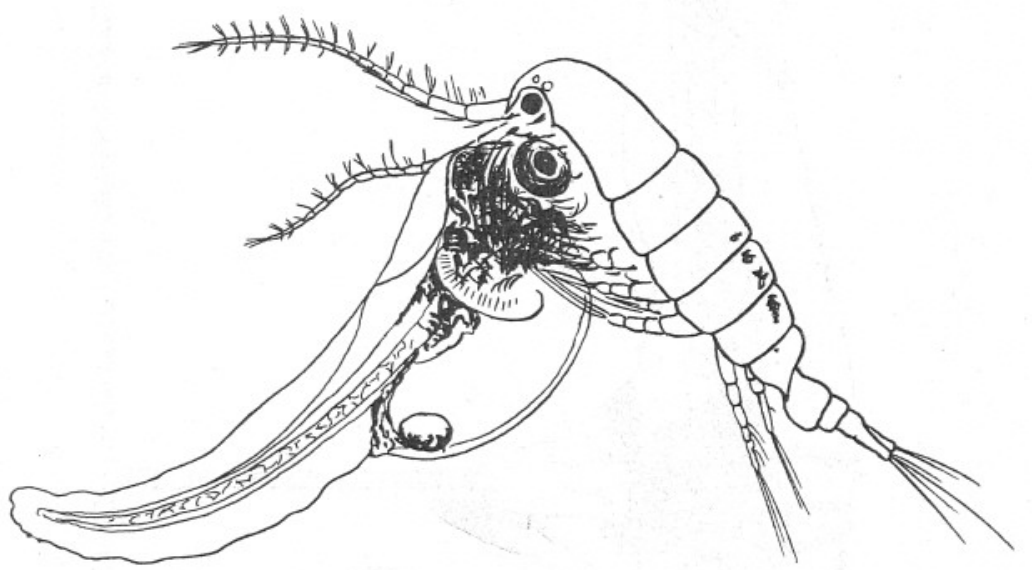

FIG. 7. Anomalocera pattersoni in Plunger Jar, catching a baby Angler.

devour the little Anglers. We already know that many jelly fishes and Pleurobrachia besides Sagitta and Tomopteris will readily eat small fishes (Lebour, 1922, 1923). The list steadily grows. Daily we are finding out that plankton organisms are to a large extent carnivorous, and this fact has far-reaching effects. We no longer wonder at the enormous number of eggs laid by one individual fish when we realise more and more the number of enemies it has besides all the physical dangers appertaining to its environment, but apart from this it is now shown that delicate plankton organisms can feed on such solid diet that it is no longer merely a question of continually satisfying hunger by swallowing thousands of minute unicellular organism, but it is an established fact that one large meal may be taken, that meal probably lasting the animal for a long period. The most delicate of all the plankton animals are those best able to take care of themselves by catching and eating solid food as large 


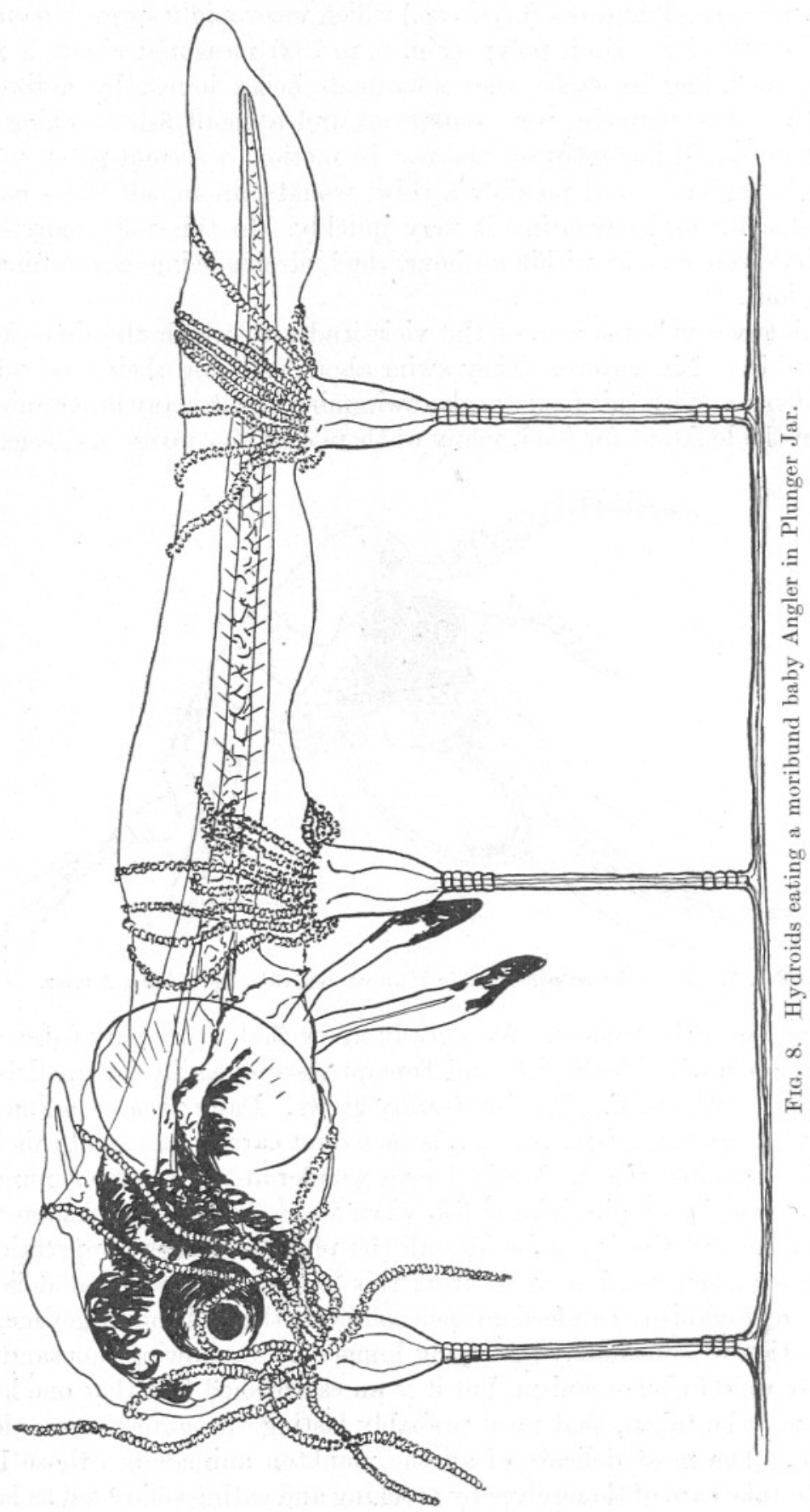


or larger than their own bodies. It is probable that many more of these plankton organisms than we realise satisfy their hunger in this way. Positive evidence is wanted, and observations on living animals should be undertaken whenever possible to establish these important facts, and in this way we shall learn the true natural history of the sea.
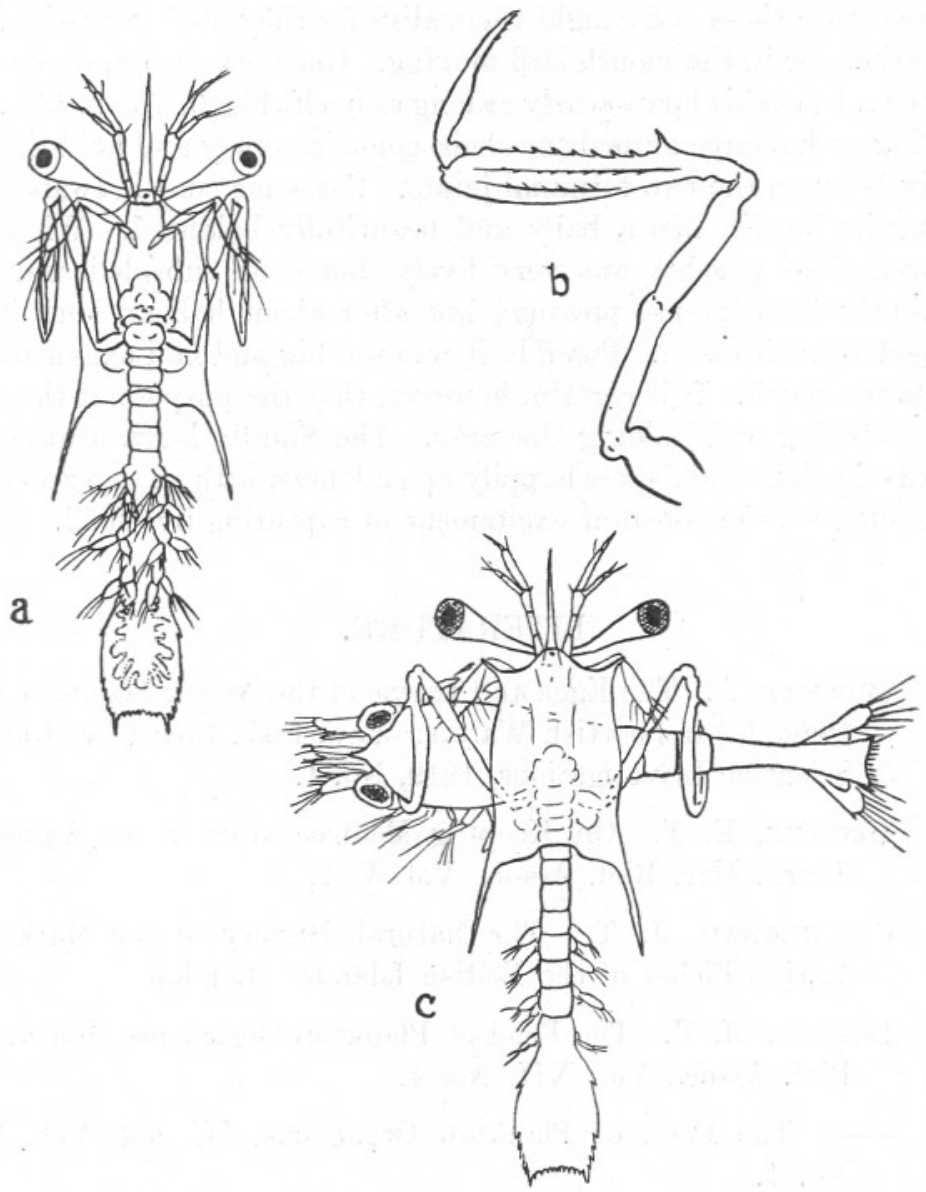

FIG. 9. Larva of Squilla in Plunger Jar.

(a) As seen at the top of the jar.

(b) Predaceous claw.

(c) Catching a Upogebia larva.

In this connexion some observations on Squilla larvæ in another Plunger Jar are interesting. The larvæ of Squilla Desmaresti in the "Alima" stage were taken from the plankton, Young Fish Trawl, L4, 27.8.24, measuring about $5 \mathrm{~mm}$. in length and placed in the jar. Some 
of these lived for several weeks, always keeping near the surface and continually in motion, springing up and down with their abdominal appendages always moving and the large chelate predaceous claws kept close to the sides, occasionally to be spread out. With the Squilla at the top of the jar were many copepods, chiefly Temora longicornis, the commonest copepod in the plankton at that time. The Squilla undoubtedly ate these and caught them alive for they were very often seen inside them or in the mouth still moving. Once one of $5 \mathrm{~mm}$. was seen to catch a Upogebia larva nearly as long as itself (Fig. 9, a-c, p. 733). For catching such a large animal the chelæ come into play and hold the prey tightly between the two terminal joints. For some time it swam about holding its burden like a baby and beautifully balanced. When first captured the Upogebia was very lively, but soon subsided and died, apparently from intense pressure, but after about half an hour it was dropped and not eaten. Possibly it was too big and had exhausted the Squilla too much. It is certain, however, that the purpose of the chelæ is for catching and holding the prey. The Squilla larva always goes towards the light and dances happily up and down with an eager alertness which suggests the constant excitement of capturing live food.

\section{LITERATURE.}

1919. Bowman, A. The Eggs and Larvæ of the Angler (Lophius piscatorius L.) in Scottish Waters. Rep. Fish. Board for Scotland, Scientific Investigations, 1919, No. 1.

1898. Browne, E. T. On Keeping Medusæ alive in an Aquarium. Journ. Mar. Biol. Assoc., Vol. V, 2.

1896. Cunningham, J. T. The Natural History of the Marketable Marine Fishes of the British Islands. London.

1922. Lebour, M. V. The Food of Plankton Organisms, Journ. Mar. Biol. Assoc., Vol. XII, No. 4.

1923. - The Food of Plankton Organisms, II, ibid. Vol. XIII, No. 1.

1924. Marshall, S. The Food of Calanus finmarchicus during 1923. Ibid. Vol. XIII, No. 2.

1923. T̊̊ning, A. V. Lophius-Report on the Danish Oceanographical Exp., 1908-10, to the Mediterranean and Adjacent Seas, Vol. II, Biology, A 10.

1911. Williamson, H. C. Notes on the Eggs of the Angler, Rep. Fish. Board for Scotland, XXVIII. 